\title{
Tungsten Oxide and Polyaniline Composite Fabricated by Surfactant-Templated Electrodeposition and Its Use in Supercapacitors
}

\author{
Benxue Zou, ${ }^{1}$ Shengchen Gong, ${ }^{1}$ Yan Wang, ${ }^{1}$ and Xiaoxia Liu ${ }^{2}$ \\ ${ }^{1}$ Department of Chemical Engineering, Liaodong University, Dandong 118003, China \\ ${ }^{2}$ Department of Chemistry, Northeastern University, Shenyang, China \\ Correspondence should be addressed to Benxue Zou; benxue_dd@163.com
}

Received 20 March 2014; Accepted 11 May 2014; Published 29 May 2014

Academic Editor: Yongfeng Li

Copyright (C) 2014 Benxue Zou et al. This is an open access article distributed under the Creative Commons Attribution License, which permits unrestricted use, distribution, and reproduction in any medium, provided the original work is properly cited.

Composite nanostructures of tungsten oxide and polyaniline (PANI) were fabricated on carbon electrode by electrocodeposition using sodium dodecylbenzene sulfonate (SDBS) as the template. The morphology of the composite can be controlled by changing SDBS surfactant and aniline monomer concentrations in solution. With increasing concentration of aniline in surfactant solution, the morphological change from nanoparticles to nanofibers was observed. The nanostructured $\mathrm{WO}_{3} / \mathrm{PANI}$ composite exhibited

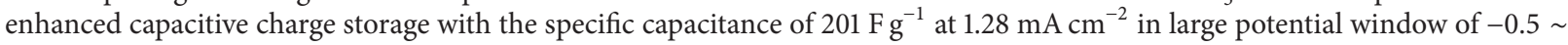
$0.65 \mathrm{~V}$ versus SCE compared to the bulk composite film. The capacitance retained about $78 \%$ when the sweeping potential rate increased from 10 to $150 \mathrm{mV} / \mathrm{s}$.

\section{Introduction}

Electrochemical capacitors (supercapacitors) have been considered as green energy storage devices which offer a number of desirable features such as fast charging/discharging within seconds and long cycle life. In supercapacitors, energy storage is mainly based on underpotential deposition (namely, double layer capacitors) or some redox process (namely, pseudocapacitors). The limitation of electrochemical capacitors to widespread application is their relative low energy density. Thus the challenge for the electrochemical capacitors is to promote the energy storage capability, meanwhile maintaining its high charging/discharging rate. Nanostructured electrode materials can meet these demands due to their high energy storage capacities and power output densities $[1,2]$.

Conducting polymers and metal oxides in nanosize scale are expected to display enhanced capacitive performance because of their large surface area, high conductivity, and light weight. The very high surface area and low charge transport resistance of nanomaterials favored faster transport of charges and ions between electrode materials and electrolyte in comparison to the bulk materials. Recently, much work has focused on the development of nanomaterials for charge storage. Zhou and coworkers demonstrated that the capacitive performances of polyaniline (PANI) were enhanced with increasing its real surface area [3]. The nanofibrous PANI prepared by the pulse galvanostatic method displayed a high specific capacitance. Nanostructured $\mathrm{NiO}$ electrodeposited on stainless steel was reported to retain good supercapacitive performance at high scan rate [4].

Since the size and morphologies of nanoscale materials have significant influence on their properties, many efforts have been devoted to fabricate nanostructured materials [5, 6]. As we know, surfactant is widely used as additive to control the structure and morphologies of conducting polymers and inorganic species [7]. The surfactant self-assembled into organized templates in the bulk of solution or at interface offers potential to produce materials that retain its molecular imprint. It was reported that polymers with nanoparticle and nonfibrillar morphologies can be obtained by using anionic surfactant as the template, while those existing as nanofibers or nanorods structures can be afforded by cationic or nonionic surfactant-assisted chemical polymerizations [8]. Conducting polymer with nanosphere structures was 
reported to be obtained through an electrochemical synthesis from a surfactant containing solution [9]. Surfactant has also been used in the preparation of inorganic species with high surface area $[10,11]$. For instance, Baeck and coworkers described an electrochemical strategy for the formation of thin nanostructured $\mathrm{WO}_{3}$ films from dilute surfactant solution [12]. Brezesinski utilized supermolecular assemblies of surfactant molecules as the structure-directing template to synthesize a nanocrystal-based porous $\mathrm{TiO}_{2}$ film [13] .

Compared to single component materials, conducting polymer based nanocomposites exhibit superior properties due to the synergistic effects. Recently, $\mathrm{Hu}$ and coworkers embedded $\mathrm{SnO}_{2}$ nanoparticles in the PANI networks by in situ polymerization on surfaces of inorganic metal oxide nanoparticles; these nanocomposites showed high rate capability and cyclic stability for supercapacitor [14]. Murugan et al. demonstrated an in situ intercalation polymerization of 3,4-ethylenedioxythiophene to prepare a nanocomposite of poly(3,4-ethylenedioxythiophene) (PEDOT) and $\mathrm{MoO}_{3}$, in which the PEDOT was intercalated into layers of $\mathrm{MoO}_{3}$ [15]. Composite films of $\mathrm{WO}_{3}$ and PANI exhibited electrochromic properties with improved stability through immobilizing the oxide in the polymer matrix [16-18]. Our previous studies showed that the composites of PANI and $\mathrm{WO}_{3}$ exhibited superior electrochemical sensing and pseudocapacitive properties compared to the respective single component $[19,20]$. A model supercapacitor assembled by the obtained $\mathrm{WO}_{3} / \mathrm{PANI}$ composite as the negative electrode material displayed a significantly promoted energy density and improved cyclic stability. In this work, we present a simple and convenient method to fabricate PANI and tungsten oxide nanostructured composites on carbon electrode by electrocodeposition with sodium dodecylbenzene sulfonate (SDBS) surfactant as the template. Morphologies of the composites were investigated by scanning electron microscopy (SEM), while cyclic voltammetry and chronopotentiometry (CP) were carried out to study capacitive properties of the composites.

\section{Experimental}

2.1. Materials and Instrumentation. Aniline was purified by distillation before use. All other chemicals were of analytical grade and used as received. Electrochemical experiments were conducted with a multichannel potentiostat (VMP3, Bio-Logic-Science Instruments) in a three-electrode electrolytic cell. The reference and counter electrodes were saturated calomel electrode (SCE) and platinum plate $\left(\mathrm{ca} .1 \mathrm{~cm}^{2}\right)$, respectively. Carbon cloth purchased from SGL (Germany) with geometric area of $0.78 \mathrm{~cm}^{2}$ was used as the working electrode. All potentials are relative to the SCE.

2.2. Composite Films Preparation. Composite films of $\mathrm{WO}_{3} / \mathrm{PANI}$ were electrochemically deposited on carbon substrates by cyclic voltammetry. A potential range between -0.6 and $0.9 \mathrm{~V}$ at $50 \mathrm{mV} / \mathrm{s}$ was used. Prior to the deposition of the film, the carbon substrates were cleaned by water and acetone and then cleaned by potential dynamic scanned from -1.0 to $1.0 \mathrm{~V}$ for 2 cycles in $1 \mathrm{M} \mathrm{H}_{2} \mathrm{SO}_{4}$. All the films were grown by 25 cyclic voltammetric scans and then rinsed with distilled water.

The solution used for composite film deposition contained tungsten acid $(0.15 \mathrm{M}), \mathrm{H}_{2} \mathrm{O}_{2}(0.04 \mathrm{M})$, and $\mathrm{H}_{2} \mathrm{SO}_{4}$ $(0.5 \mathrm{M})$ with different amount of aniline and sodium dodecylbenzene sulfonate (SDBS). SDBS concentrations of $0,1.3$, 2.6, 5.2, 57.4, and $130 \mathrm{mM}$ were used and the films produced were denoted as $\mathrm{WP}^{\mathrm{S} 0}, \mathrm{WP}^{\mathrm{S1} .3}, \mathrm{WP}^{\mathrm{S} 2.6}, \mathrm{WP}^{\mathrm{S} 5.2}, \mathrm{WP}^{\mathrm{S57.4}}$, and $\mathrm{WP}^{\mathrm{S} 130}$

The composite films prepared from solutions containing $57.4 \mathrm{mM}$ SDBS in the presence of 75 and $175 \mathrm{mM}$ aniline were denoted as $\mathrm{WP}^{\mathrm{A} 75 / \mathrm{S} 57.4}$ and $\mathrm{WP}^{\mathrm{A} 175 / \mathrm{S} 57.4}$, while those from solutions containing $130 \mathrm{mM}$ SDBS in the presence of 75 and $125 \mathrm{mM}$ aniline were denoted as $\mathrm{WP}^{\mathrm{A} 75 / \mathrm{S} 130}$ and $\mathrm{WP}^{\mathrm{A} 125 / \mathrm{S} 130}$, respectively.

2.3. Composite Film Characterization. Pseudocapacitive behaviors of the films were studied by cyclic voltammetry and chronopotentiometry (CP) in $1 \mathrm{M} \mathrm{H}_{2} \mathrm{SO}_{4}$ electrolyte. The morphologies of the samples were investigated by scanning electron microscopy (SEM, LEO SUPRA 35). The FT-IR spectra were recorded using Spectrum One FT-IR spectrometer (Perkin-Elmer, USA) with $\mathrm{KBr}$ pellets of powder samples scraped off from $\mathrm{C}$ substrate. The UV-vis spectra were recorded on composite films deposited on ITO using Lambda $35 \mathrm{UV} /$ vis spectrophotometer.

\section{Results and Discussions}

3.1. Influence of SDBS Surfactant Concentration on Morphology of the Composite. Electrocodeposition of $\mathrm{WO}_{3}$ and PANI was conducted through 25 cyclic voltammetric scans between -0.6 and $0.9 \mathrm{~V}$ at $50 \mathrm{mV} / \mathrm{s}$ in solutions containing various concentrations of SDBS surfactant. Surface morphologies of the composite films $\mathrm{WP}^{\mathrm{S} 0}, \mathrm{WP}^{\mathrm{S1.3}}, \mathrm{WP}^{\mathrm{S} 2.6}, \mathrm{WP}^{\mathrm{S5} .2}, \mathrm{WP}^{\mathrm{S} 57.4}$, and $\mathrm{WP}^{\mathrm{S} 130}$, obtained from $0,1.3,2.6,5.2,57.4$, and $130 \mathrm{mM}$ SDBS, were investigated by SEM (Figure 1). As can be seen in Figure 1, the particle size decreases with increasing concentration of SDBS in solution at lower concentration range $(<5.2 \mathrm{mM})$. The $\mathrm{WP}^{\mathrm{S} .6}$ and $\mathrm{WP}^{\mathrm{S} .2}$ composites show the smallest size of nanoparticles having average diameter of 10 $50 \mathrm{~nm}$. At the higher concentration of SDBS (e.g., $130 \mathrm{mM}$ ), particular large spherical particles assembled from 1D oriented nanoribbon-like structure were observed (Figure 1(f)), which indicate that the morphology of the composite is controllable by SDBS surfactant.

As we know, the SDBS surfactant consists of hydrophilic sulfonic acid and long hydrophobic alkyl chain. The spherical micelles are formed at the critical micelle concentration (cmc). The $\mathrm{cmc}$ for SDBS is about $1.5 \mathrm{mM}$ in aqueous solution [21]. With the increase of SDBS concentration in solution, the spherical micelles self-assemble into larger spherical, cylindrical aggregates in solution, or flat bilayer micelles on the surface [22]. The aggregated micelles are negatively charged outside, so the anilinium cation can form complex structures by electrostatic interaction. The incorporation of aniline monomer with surfactant causes the aggregated micelle to swell and enlarge [7]. These complexes were assumed to serve 


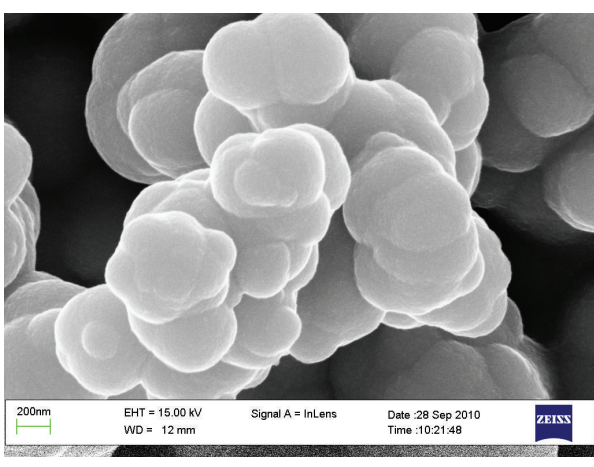

(a)

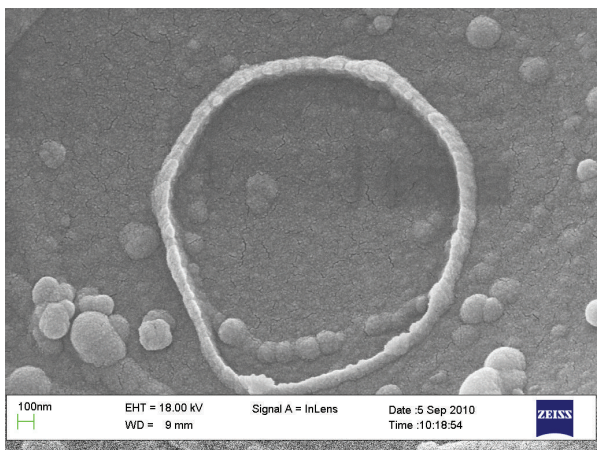

(c)

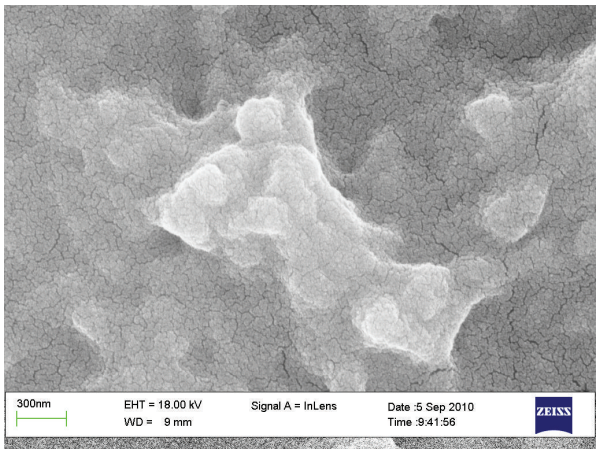

(e)

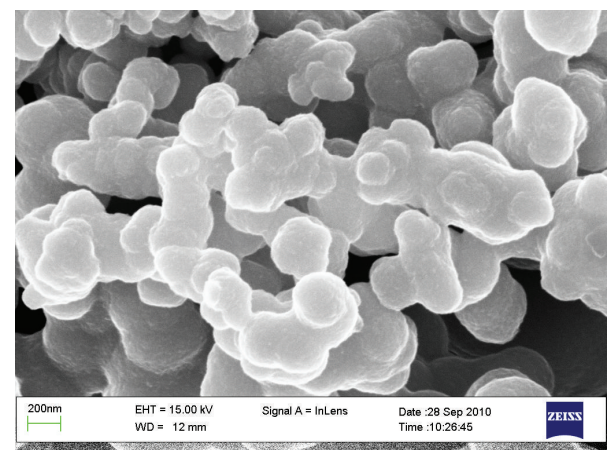

(b)

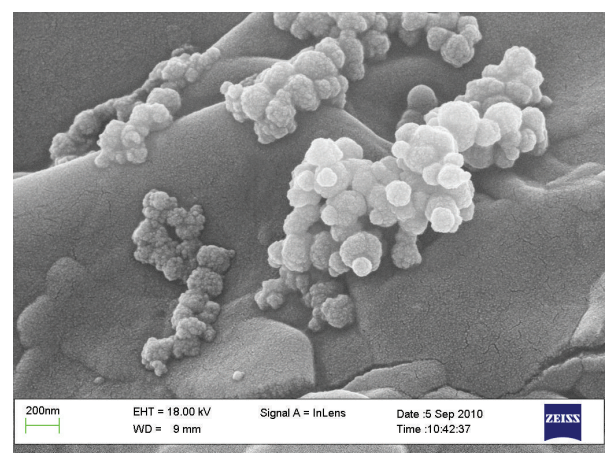

(d)

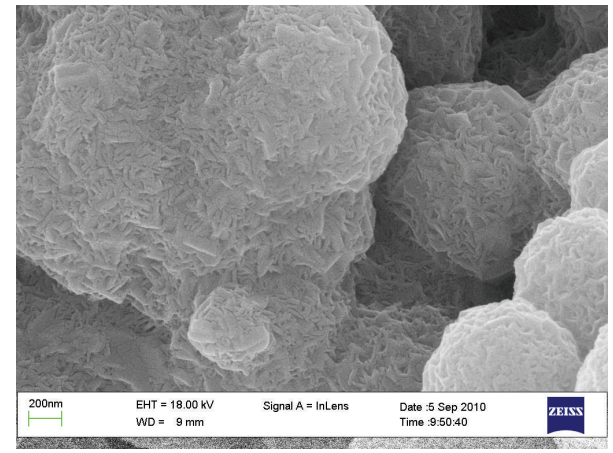

(f)

Figure 1: SEM images of $\mathrm{WO}_{3} / \mathrm{PANI}$ films (a) $\mathrm{WP}^{\mathrm{S} 0}$; (b) $\mathrm{WP}^{\mathrm{S1.3}}$; (c) $\mathrm{WP}^{\mathrm{S} 2.6}$; (d) $\mathrm{WP}^{\mathrm{S5.2}}$; (e) $\mathrm{WP}^{\mathrm{S} 57.4}$; and (f) $\mathrm{WP}^{\mathrm{S} 130}$.

as structure template in the electrochemical polymerization process. At the lower SDBS concentrations (about 2 4 cmc), the smaller spherical micelle may facilitate the smaller particle size of the composite formed on the electrode (Figures 1(c) and $1(\mathrm{~d})$ ). With the increasing concentration of SDBS (e.g., $130 \mathrm{mM}$ ), the micelle becomes larger and more SDBS may aggregate more aniline monomers inside/outside the micelle, which more likely lead to the original 1D direction growth of the polymers as shown in Figure 1(f).

3.2. Influence of Aniline Concentration on Morphology of the Composite. It is interesting to note that aniline concentration also significantly influences morphology of the composite. Figure 2 presents the surface morphologies of $\mathrm{WP}^{\mathrm{A} 75 / \mathrm{S57.4}}$ and WP $\mathrm{W}^{\mathrm{A} 175 / \mathrm{S} 57.4}$ films afforded from $57.4 \mathrm{mM}$ SDBS solutions with 75 and $175 \mathrm{mM}$ aniline and $\mathrm{WP}^{\mathrm{A} 75 / \mathrm{S} 130}$ and $\mathrm{WP}^{\mathrm{A} 125 / \mathrm{S} 130}$ films afforded from $130 \mathrm{mM}$ SDBS solutions with 75 and $125 \mathrm{mM}$ aniline, respectively. The composite particles tend to be of one-dimensional arrangement when aniline concentration increases in solution. Cationic anilinium is considered to be amphiphilic molecular because of its cationic head group and hydrophobic phenyl ring [23]. As the aniline concentration increases, more aniline monomer will be involved in micelle formation, and the competition between surfactant/monomer supermolecules and aniline monomer itself micelles may take place. Thus the increase of aniline concentration may exert influences on micelle compositions and structures. During the electrodeposition process, the preferentially 1D direction growth of polyaniline and the elongation of the rigid micelle result in the formation of $1 D$ arrangement of the composite. 


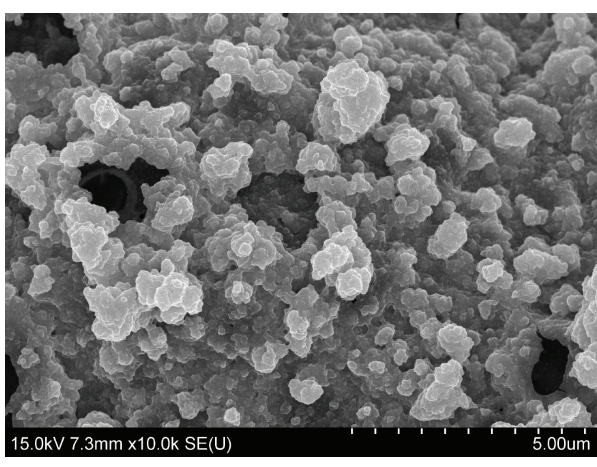

(a)

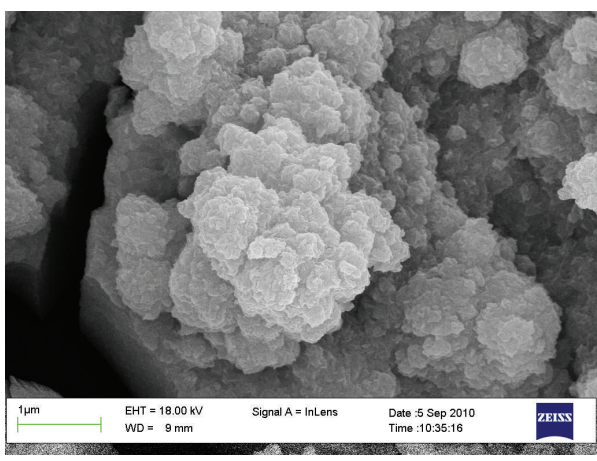

(c)

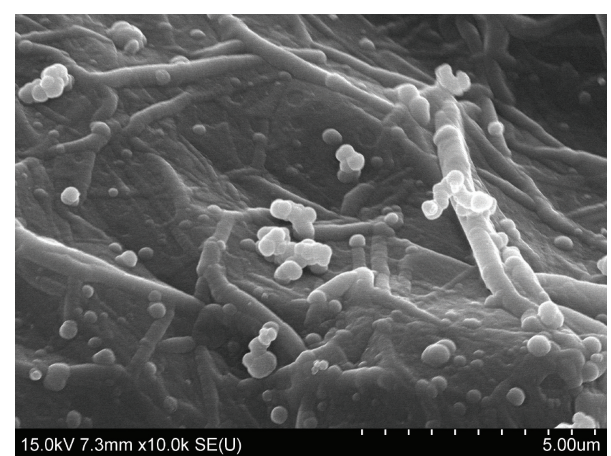

(b)

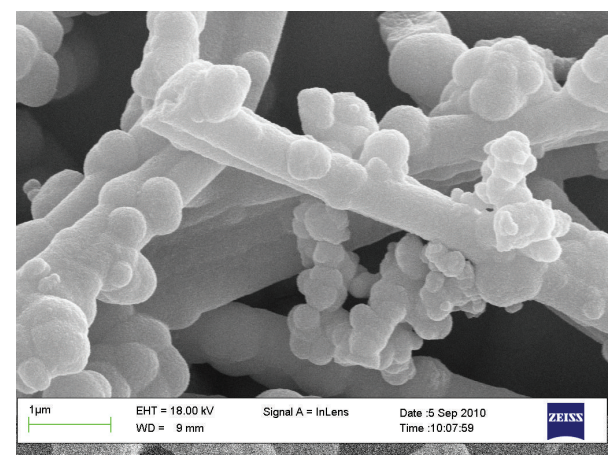

(d)

FIGURE 2: SEM images of $\mathrm{WO}_{3} / \mathrm{PANI}$ films (a) $\mathrm{WP}^{\mathrm{A} 75 / \mathrm{S} 57.4}$; (b) $\mathrm{WP}^{\mathrm{A175/S57.4}}$; (c) $\mathrm{WP}^{\mathrm{A} 75 / \mathrm{S} 130}$; and (d) WP $\mathrm{W}^{A 125 / \mathrm{S} 130}$.

Similar trends were observed on similarly prepared PANI. Figure 3 shows the SEM images of PANI films of PANI ${ }^{\mathrm{A} 75}$, $\mathrm{PANI}^{\mathrm{A} 125}$, and $\mathrm{PANI}^{\mathrm{A} 175}$ electrodeposited from solutions containing 75,125 , and $175 \mathrm{mM}$ aniline, respectively. PANI is prone to grow in $1 \mathrm{D}$ directions as the concentration of aniline increased in solution. The short PANI nanorods with average diameter of $150 \sim 200 \mathrm{~nm}$ gradually changed to long interconnected PANI nanofibers with diameter of $80 \sim$ $100 \mathrm{~nm}$.

\subsection{Influence of SDBS Concentration on Pseudocapacitive} Properties of the Composite. To investigate the pseudocapacitive properties of the composite films, cyclic voltammetric scans were conducted on $\mathrm{WP}^{\mathrm{S} 0}, \mathrm{WP}^{\mathrm{S1.3}}, \mathrm{WP}^{\mathrm{S} 2.6}, \mathrm{WP}^{\mathrm{S5} .2}$, $\mathrm{WP}^{\mathrm{S} 57.4}$, and $\mathrm{WP}^{\mathrm{S} 130}$ in $1 \mathrm{M} \mathrm{H}_{2} \mathrm{SO}_{4}$ (Figure $4(\mathrm{a})$ ). The $\mathrm{WO}_{3}$ related $\left(\mathrm{A} / \mathrm{A}^{\prime}\right)$ and PANI-related $\left(\mathrm{B} / \mathrm{B}^{\prime}\right.$ and $\left.\mathrm{C} / \mathrm{C}^{\prime}\right)$ redox pairs can be seen in Figure 4(a), similar to our previously reported $\mathrm{WO}_{3} / \mathrm{PANI}$ composite [19]. The redox pair $\mathrm{B} / \mathrm{B}^{\prime}$ which corresponds to the exchange between fully reduced (leucoemeraldine) and half-oxidized (emeraldine) PANI is a good indicator for the electrochemical activity of PANI. The currents of $\mathrm{B} / \mathrm{B}^{\prime}$ are higher for the composites made in the presence of SDBS than that from free of SDBS. When SDBS was added in the solution up to $2.6 \mathrm{mM}$, the $\mathrm{WO}_{3}$-related (A/A') peak currents on the cyclic voltammograms (CVs) of the composites were increased. However, the currents decreased with the further increase of SDBS concentration, indicating the restriction of the tungsten oxide deposition probably because of the strong electrostatic repulsive force between the negative headgroup of the surfactant micelles and tungstate anions (suggested by the micrograph of Figure 1(f)). The composite $\mathrm{WP}^{\mathrm{S} 2.6}$ exhibited higher electroactivities of both $\mathrm{WO}_{3}$ and PANI in Figure 4(a). This should be related to the nanostructure of the $\mathrm{WP}^{\mathrm{S} 2.6}$ film which may provide more opportunity for the reactive centers on the film to contact with electrolyte and so facilitate the charge transfer in the bulk of the film.

The galvanostatic charge-discharge measurements were carried out by CP on these composite films (Figure 4(b)). The $\mathrm{WO}_{3} / \mathrm{PANI}$ composite films display pseudocapacitive behaviors in a comparatively larger potential range from $-0.5 \mathrm{~V}$ to $0.65 \mathrm{~V}$ versus SCE due to the combination of electrochemical activities of $\mathrm{WO}_{3}$ and PANI. The large potential range is favored for the increase of energy density for supercapacitors. The specific capacitances of the composite films increase with the increase of SDBS concentration up to $2.6 \mathrm{mM}$ (inset of Figure $4(\mathrm{~b})$ ). The $\mathrm{CP}$ results show that $\mathrm{WP}^{\mathrm{S} 2.6}$ composite film exhibits the highest specific capacitance of $201 \mathrm{~F} / \mathrm{g}$. The inefficient contribution of $\mathrm{WO}_{3}$ to the total capacitance of the composite can be observed in the negative potential range of the $\mathrm{CP}$ curves of $\mathrm{WP}^{\mathrm{S57.4}}$ and $\mathrm{WP}^{\mathrm{S130}}$, which is in agreement with cyclic voltammetry results.

3.4. Characterization of the WP Nanocomposite. EDX and FT-IR spectra were recorded to characterize the typical nanocomposite of $\mathrm{WP}^{\mathrm{S} 2.6}$. The EDX spectrum displays the 


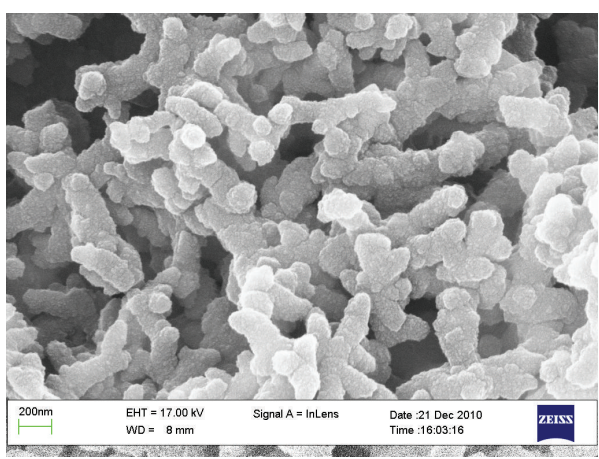

(a)

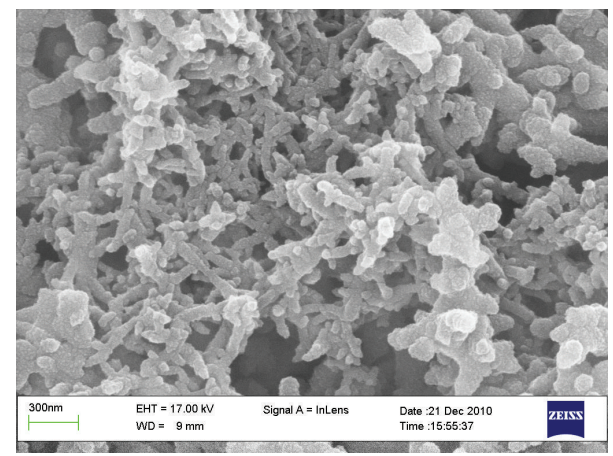

(b)

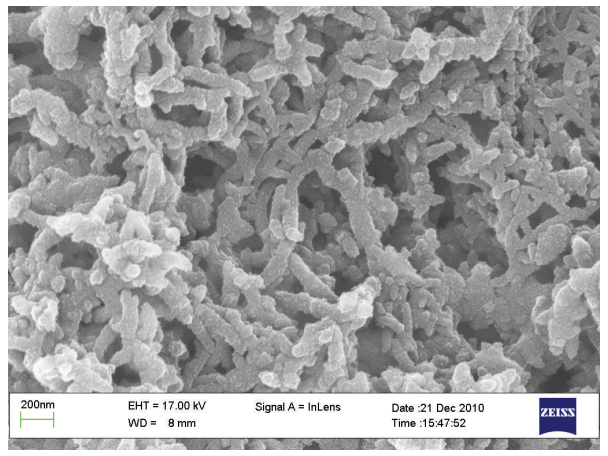

(c)

FIgUre 3: SEM images of (a) PANI ${ }^{\mathrm{A} 75}$; (b) $\mathrm{PANI}^{\mathrm{A} 125}$; and (c) PANI ${ }^{\mathrm{A175}}$.

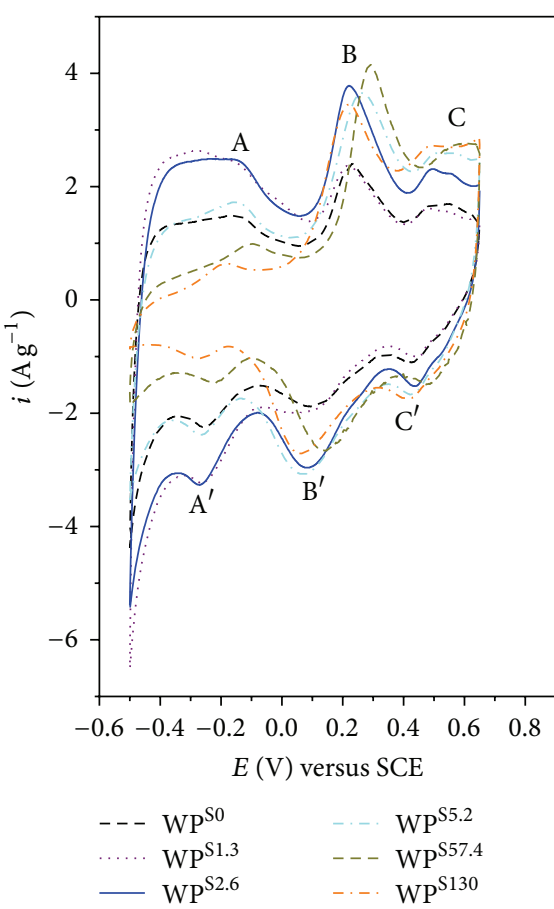

(a)

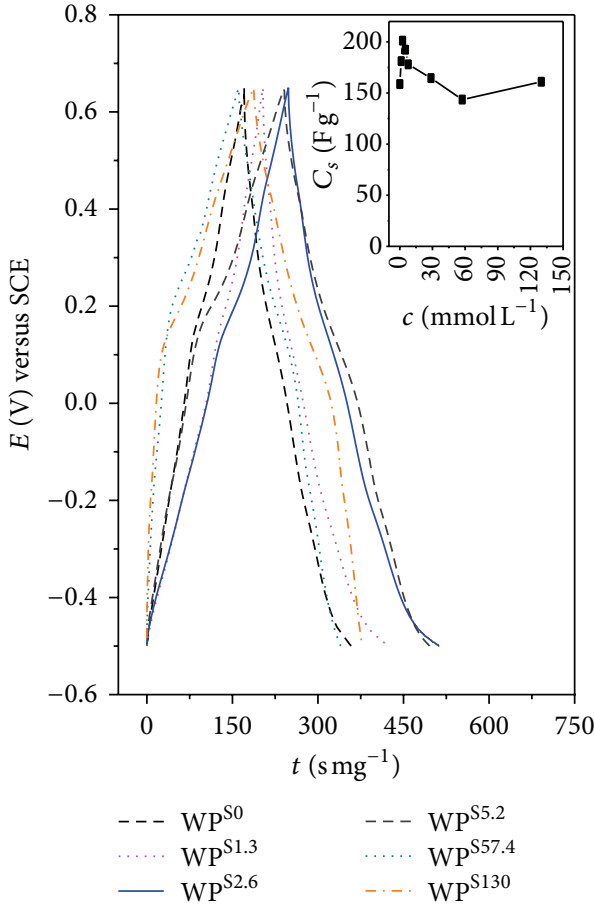

(b)

Figure 4: (a) CVs of $\mathrm{WO}_{3} / \mathrm{PANI}$ films of $\mathrm{WP}^{\mathrm{S} 0}, \mathrm{WP}^{\mathrm{S} 1.3}, \mathrm{WP}^{\mathrm{S} 2.6}, \mathrm{WP}^{\mathrm{S5.2}}$, $\mathrm{WP}^{\mathrm{S} 57.4}$, and $\mathrm{WP}^{\mathrm{S130}}$ in $1 \mathrm{M} \mathrm{H}_{2} \mathrm{SO}_{4}$. Scan rate: $10 \mathrm{mV} / \mathrm{s}$. (b) Constant current charge-discharge curves of $\mathrm{WO}_{3} / \mathrm{PANI}$ films in $1 \mathrm{M} \mathrm{H}_{2} \mathrm{SO}_{4}$ at $1.28 \mathrm{~mA} / \mathrm{cm}^{2}$. Inset shows the specific capacitance of WO $3 / \mathrm{PANI}$ electrodes obtained from solutions containing SDBS in various concentrations. 


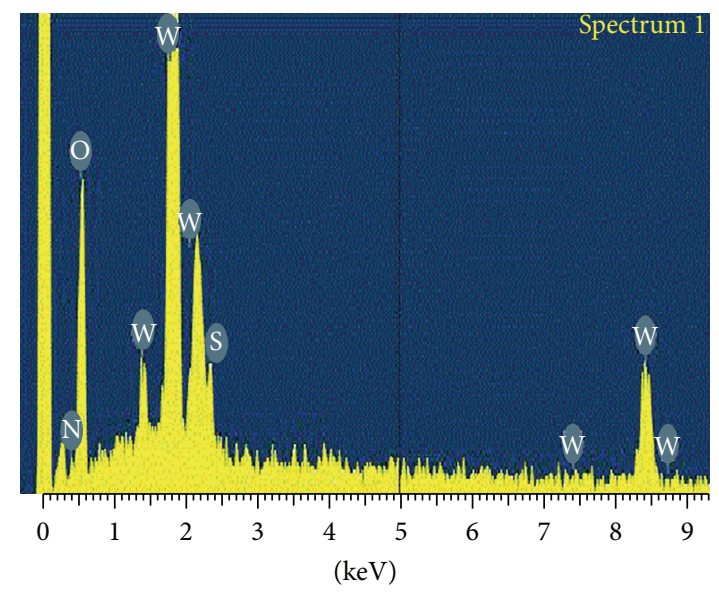

Full scale $143 \mathrm{cts}$ cursor. $4.954 \mathrm{keV}$ ( $7 \mathrm{cts}$ )

(a)

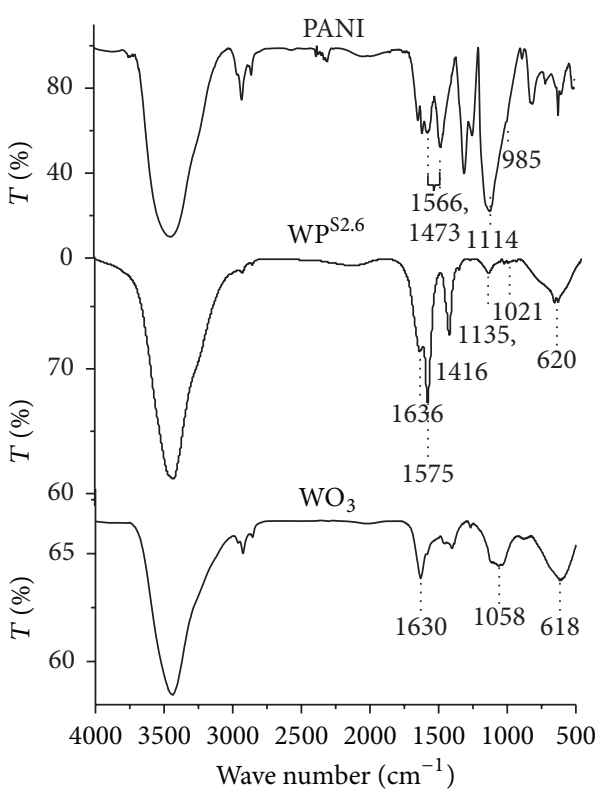

(b)

FIGURE 5: (a) EDX spectrum of $\mathrm{WP}^{\mathrm{S} 2.6}$, (b) FT-IR spectra of PANI, $\mathrm{WP}^{\mathrm{S} 2.6}$, and $\mathrm{WO}_{3}$.

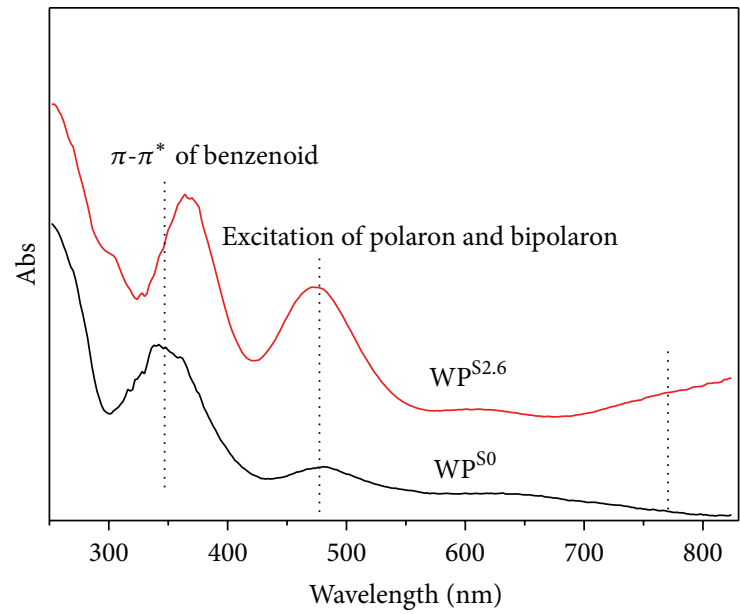

FIGURE 6: UV-vis spectra of the $\mathrm{WP}^{\mathrm{S} 2.6}$ and $\mathrm{WP}^{\mathrm{S} 0}$.

signals of $\mathrm{W}$ from $\mathrm{WO}_{3}$ and $\mathrm{N}$ from PANI in Figure 5(a). From FT-IR spectra in Figure 5(b), $\mathrm{WP}^{\mathrm{S} 2.6}$ exhibits characteristic vibrations of both PANI and $\mathrm{WO}_{3}$. The peaks at 1575 and $1416 \mathrm{~cm}^{-1}$ are due to the stretching vibration of quinoid $(\mathrm{N}=\mathrm{Q}=\mathrm{N})$ and benzenoid $(\mathrm{N}-\mathrm{B}-\mathrm{N})$ rings, respectively [23], which appear at 1566 and $1473 \mathrm{~cm}^{-1}$ in the spectrum of PANI. Bands at $1135 \mathrm{~cm}^{-1}$ in the spectrum of WP $\mathrm{W}^{\$ 2.6}$ and $1114 \mathrm{~cm}^{-1}$ in that of PANI are attributed to the characteristic band of protonated PANI [24]. As can be observed in Figure 5(b), the intensity of the peak at $1114 \mathrm{~cm}^{-1}$ in the spectrum of PANI is rather higher than that of the $\mathrm{WP}^{\mathrm{S} .6}$. This is mainly attributed to the consumption of $\mathrm{H}^{+}$near or on the electrode surface by
$\mathrm{WO}_{3}$ deposition process, which results in the decrease of the protonated degree of PANI in the composite. The deposition process of $\mathrm{WO}_{3}$ can be represented by the following equation [25]:

$$
\begin{aligned}
& 2 \mathrm{WO}_{4}{ }^{2-}+4 \mathrm{H}_{2} \mathrm{O}_{2}+2 \mathrm{H}^{+} \longrightarrow \mathrm{W}_{2} \mathrm{O}_{11}{ }^{2-}+5 \mathrm{H}_{2} \mathrm{O} \\
& \mathrm{W}_{2} \mathrm{O}_{11}{ }^{2-}+(2+x) \mathrm{H}^{+}+x \mathrm{e}^{-} \\
& \longrightarrow 2 \mathrm{WO}_{3}+\left(\frac{1+x}{2}\right) \mathrm{H}_{2} \mathrm{O}+\left(\frac{2-x}{4}\right) \mathrm{O}_{2} .
\end{aligned}
$$

The absorption peak at $1636 \mathrm{~cm}^{-1}$ for $\mathrm{WP}^{\mathrm{S2.6}}$, corresponding to the peak at $1630 \mathrm{~cm}^{-1}$ for $\mathrm{WO}_{3}$, is attributed to the in-plane bending mode $\delta\left(\mathrm{H}_{2} \mathrm{O}\right)$ of structure water [26]. The $\mathrm{O}-\mathrm{W}-\mathrm{O}$ stretching mode appears as a broad band around $620 \mathrm{~cm}^{-1}$ which is similar to that of $\mathrm{WO}_{3}$ at $618 \mathrm{~cm}^{-1}$ [27]. The broad peak at $1058 \mathrm{~cm}^{-1}$ in the $\mathrm{WO}_{3}$ spectrum was overlapped with the characteristic protonated PANI peak at $1135 \mathrm{~cm}^{-1}$ in the spectrum of $\mathrm{WP}^{\mathrm{S2.6} \text {. }}$

The UV-vis spectra of the $\mathrm{WP}^{\mathrm{S} 2.6}$ (deposited on ITO) were shown in Figure 6, together with the spectra of $\mathrm{WP}^{\mathrm{S} 0}$. The band at $320-360 \mathrm{~nm}$ corresponds to $\pi-\pi^{*}$ electron transition of benzenoid segments, which can be assigned to the intermediate state of PANI between leucoemeraldine and emeraldine [8]. The bands at ca. 470 and ca. $800 \mathrm{~nm}$ are concerned with the doping level and formation of polarons and bipolarons (quinoid segments), respectively. From Figure 6, the band at $320-360 \mathrm{~nm}$ in the spectra of $\mathrm{WP}^{\mathrm{S2} .6}$ moved to the long wavelength (red shift) in comparison with $\mathrm{WP}^{\mathrm{S} 0}$, likely because of the increasing delocalized degree of $\pi-\pi^{*}$ conjugate system in $\mathrm{WP}^{\mathrm{S2.6}}$. Furthermore, the $\mathrm{WP}^{\mathrm{S} 2.6}$ demonstrated the increased intensity of the band at ca. $470 \mathrm{~nm}$ and the absorption band 


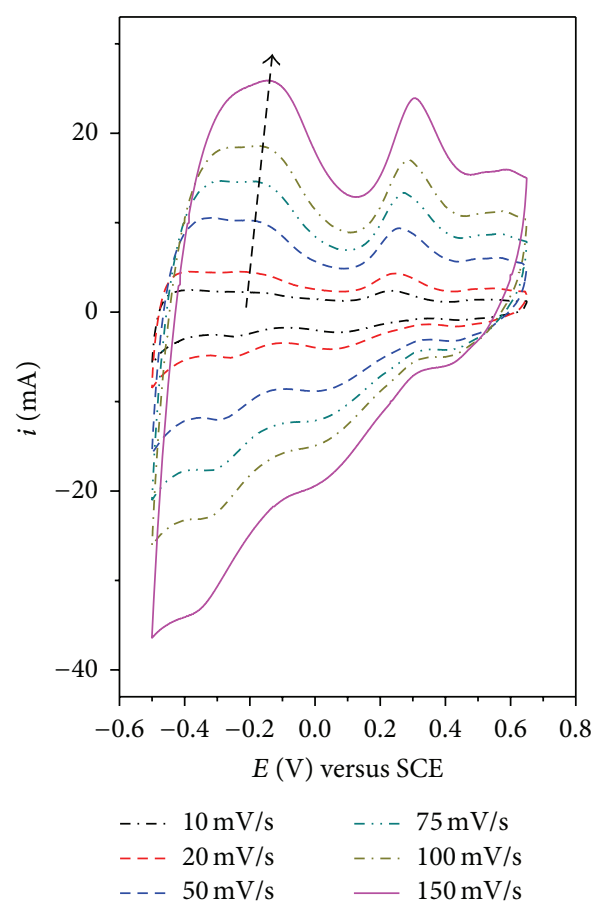

(a)

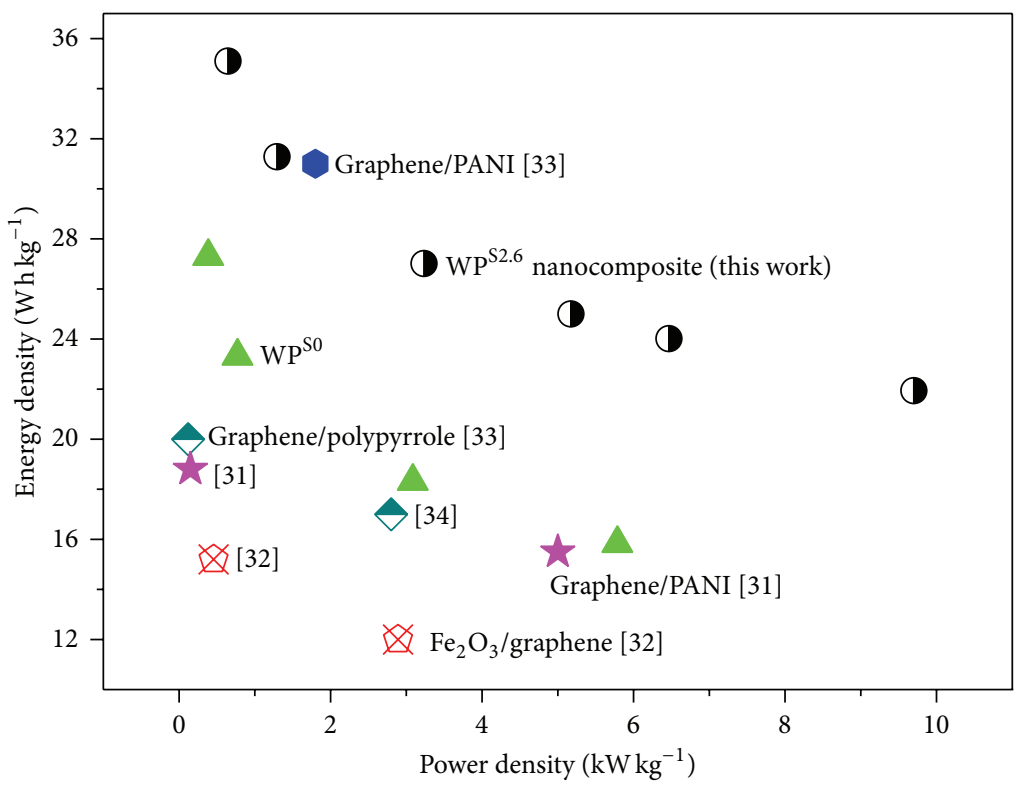

(b)

FIgURE 7: (a) CVs of $\mathrm{WP}^{52.6}$ in $1 \mathrm{M} \mathrm{H}_{2} \mathrm{SO}_{4}$ at different scan rates from 10 to $150 \mathrm{mV} / \mathrm{s}$ as indicated by the arrow in the figure. (b) Ragone plots of nano- $\mathrm{WP}^{\mathrm{S} 2.6}$, bulk $\mathrm{WP}^{\mathrm{S0}}$ films, and the value of recently reported composite films for comparison.

at around $800 \mathrm{~nm}$ with a long tail, which correspond to the polaron bands related transitions, implying the emeraldine salt form of PANI in $\mathrm{WP}^{\mathrm{S} .6}[5,28]$.

\subsection{Pseudocapacitive Properties of the WP Nanocomposite.} Figure 7 (a) presents the cyclic voltammograms of the $\mathrm{WP}^{\mathrm{S} .6}$ composite film at scan rates of $10 \sim 150 \mathrm{mV} / \mathrm{s}$ with potential range from $-0.5 \mathrm{~V}$ to $0.65 \mathrm{~V}$. The mirror-like images of CV curves reveal the typical pseudocapacitive behavior with rapid current response on voltage reversal. The CV curves still remain nearly mirror-like image without obvious distortion even at scan rate of $150 \mathrm{mV} / \mathrm{s}$. This excellent rate capability should be mainly attributed to the large accessible surface areas and low charge transport resistance provided by the nanostructures of the composite which facilitate electrolyte ion and charge transport during charge-discharge process. The area capacitance is calculated to be $0.284 \mathrm{~F} / \mathrm{cm}^{2}$ at thescan rate of $10 \mathrm{mV} / \mathrm{s}$ and $0.222 \mathrm{~F} / \mathrm{cm}^{2}$ at $150 \mathrm{mV} / \mathrm{s}$. The capacitance retained about $78 \%$ when the scan rate increased from 10 to $150 \mathrm{mV} / \mathrm{s}$, which is comparable to those of previously reported nano- $\mathrm{MnO}_{2}$ (retained about $46 \%$ from 10 to $150 \mathrm{mV} / \mathrm{s}$ ) [29], ordered mesoporous $\mathrm{WO}_{3-x}$ (about $45 \%$ from 10 to $50 \mathrm{mV} / \mathrm{s}$ ) [30], and polyaniline stabilized $\mathrm{WO}_{3}$ nanocomposite (about $36 \%$ from 5 to $100 \mathrm{mV} / \mathrm{s}$ ) [18].

Constant current charge-discharge experiments were conducted on $\mathrm{WP}^{\mathrm{S} 2.6}$ and $\mathrm{WP}^{\mathrm{S} 0}$ by chronopotentiometry at various current densities. Ragone plots were obtained based on these experiments (Figure $7(\mathrm{~b})$ ). The $\mathrm{WP}^{\mathrm{S} .6}$ film has much higher energy density than $\mathrm{WP}^{\mathrm{S} 0}$ film at the same power density. The energy density of the $\mathrm{WP}^{\mathrm{S} 2.6}$ electrode is found to be $37 \mathrm{Wh} \mathrm{kg}^{-1}$ at the power density of $650 \mathrm{~W} \mathrm{~kg}^{-1}$ and $25 \mathrm{Wh} \mathrm{kg}^{-1}$ at $5 \mathrm{~kW} \mathrm{~kg}^{-1}$, which is $46 \%$ higher than that of $\mathrm{WP}^{\mathrm{S} 0}$ film at $650 \mathrm{~W} \mathrm{~kg}^{-1}$ and $56 \%$ higher at $5 \mathrm{~kW} \mathrm{~kg}^{-1}$. Moreover, the nanocomposite $\mathrm{WP}^{\mathrm{S} 2.6}$ film also shows higher energy density and power density than other recently reported values of composite films (Figure 7(b)) [3134].

\section{Conclusions}

The electrocodeposition of tungsten oxide and polyaniline composite nanostructures using SDBS surfactant as the template showed that both the SDBS and aniline monomer in the deposition solution could act as the structure direction reagent in the formation of the nanostructured composite film. The morphology of the composite is controllable by SDBS and aniline monomers in solution. The resulting composite film with spherical nanoparticles was formed from 2.6 5.2 mM SDBS (about 2 4 times of $\mathrm{cmc}$ ). With the concentration of aniline monomer increased in the solution, one-dimensional growth trends were observed for both of PANI and the composites. Nanostructured composite of $\mathrm{WP}^{\mathrm{S} 2.6}$ obtained from the solution containing 2.6 mM SDBS displayed the best capacitive performance and rate capability. The specific capacitance can be retained about 78\% with the increasing of sweeping potential rate for cyclic voltammetric scans from 10 to $150 \mathrm{mV} / \mathrm{s}$, which make it useful for negative electrode for supercapacitors. 


\section{Conflict of Interests}

The authors declare that there is no conflict of interests regarding the publication of this paper.

\section{Acknowledgment}

This work was supported by Liaoning Province new Ph.D. startup fund (Project no. 20131039).

\section{References}

[1] S. R. Sivakkumar, W. J. Kim, J.-A. Choi, D. R. MacFarlane, M. Forsyth, and D.-W. Kim, "Electrochemical performance of polyaniline nanofibres and polyaniline/multi-walled carbon nanotube composite as an electrode material for aqueous redox supercapacitors," Journal of Power Sources, vol. 171, no. 2, pp. 1062-1068, 2007.

[2] C. Meng, C. Liu, and S. Fan, "Flexible carbon nanotube/ polyaniline paper-like films and their enhanced electrochemical properties," Electrochemistry Communications, vol. 11, no. 1, pp. 186-189, 2009.

[3] H. Zhou, H. Chen, S. Luo, G. Lu, W. Wei, and Y. Kuang, "The effect of the polyaniline morphology on the performance of polyaniline supercapacitors," Journal of Solid State Electrochemistry, vol. 9, no. 8, pp. 574-580, 2005.

[4] K. R. Prasad and N. Miura, "Electrochemically deposited nanowhiskers of nickel oxide as a high-power pseudocapacitive electrode," Applied Physics Letters, vol. 85, no. 18, pp. 4199-4201, 2004.

[5] H. Ding, M. Wan, and Y. Wei, "Controlling the diameter of polyaniline nanofibers by adjusting the oxidant redox potential," Advanced Materials, vol. 19, no. 3, pp. 465-469, 2007.

[6] M. J. Giz, S. L. de Albuquerque Maranhão, and R. M. Torresi, "AFM morphological study of electropolymerised polyaniline films modified by surfactant and large anions," Electrochemistry Communications, vol. 2, no. 6, pp. 377-381, 2000.

[7] A. D. W. Carswell, E. A. O’Rear, and B. P. Grady, "Adsorbed surfactants as templates for the synthesis of morphologically controlled polyaniline and polypyrrole nanostructures on flat surfaces: from spheres to wires to flat films," Journal of the American Chemical Society, vol. 125, no. 48, pp. 14793-14800, 2003.

[8] V. Eskizeybek, F. Sari, H. Gülce, A. Gülce, and A. Avci, "Preparation of the new polyaniline/ZnO nanocomposite and its photocatalytic activity for degradation of methylene blue and malachite green dyes under UV and natural sun lights irradiations," Applied Catalysis B: Environmental, vol. 119-120, pp. 197-206, 2012.

[9] J. A. Raj, J. Mathiyarasu, C. Vedhi, and P. Manisankar, "Electrochemical synthesis of nanosize polyaniline from aqueous surfactant solutions," Materials Letters, vol. 64, no. 8, pp. 895897, 2010.

[10] M. Deepa, A. K. Srivastava, K. N. Sood, and S. A. Agnihotry, "Nanostructured mesoporous tungsten oxide films with fast kinetics for electrochromic smart windows," Nanotechnology, vol. 17, no. 10, pp. 2625-2630, 2006.

[11] M. Deepa, A. K. Srivastava, and S. A. Agnihotry, "Influence of annealing on electrochromic performance of template assisted, electrochemically grown, nanostructured assembly of tungsten oxide," Acta Materialia, vol. 54, no. 17, pp. 4583-4595, 2006.
[12] S.-H. Baeck, K.-S. Choi, T. F. Jaramillo, G. D. Stucky, and E. W. McFarland, "Enhancement of photocatalytic and electrochromic properties of electrochemically fabricated mesoporous $\mathrm{WO}_{3}$ thin films," Advanced Materials, vol. 15, no. 15, pp. 1269-1273, 2003.

[13] T. Brezesinski, J. Wang, J. Polleux, B. Dunn, and S. H. Tolbert, "Templated nanocrystal-based porous $\mathrm{TiO}_{2}$ films for nextgeneration electrochemical capacitors," Journal of the American Chemical Society, vol. 131, no. 5, pp. 1802-1809, 2009.

[14] Z.-A. Hu, Y.-L. Xie, Y.-X. Wang, L.-P. Mo, Y.-Y. Yang, and Z.$\mathrm{Y}$. Zhang, "Polyaniline $/ \mathrm{SnO}_{2}$ nanocomposite for supercapacitor applications," Materials Chemistry and Physics, vol. 114, no. 2-3, pp. 990-995, 2009.

[15] A. V. Murugan, A. K. Viswanath, C. S. Gopinath, and K. Vijayamohanan, "Highly efficient organic-inorganic poly(3,4ethylenedioxythiophene)- molybdenum trioxide nanocomposite electrodes for electrochemical supercapacitor," Journal of Applied Physics, vol. 100, no. 7, Article ID 074319, 2006.

[16] P. K. Shen, H. T. Huang, and A. C. C. Tseung, "Study of tungsten trioxide and polyaniline composite films. I. Electrochemical and electrochromic behavior," Journal of the Electrochemical Society, vol. 139, no. 7, pp. 1840-1845, 1992.

[17] N. Parvatikar, S. Jain, S. Khasim, M. Revansiddappa, S. V. Bhoraskar, and M. V. N. A. Prasad, "Electrical and humidity sensing properties of polyaniline/ $\mathrm{WO}_{3}$ composites," Sensors and Actuators B: Chemical, vol. 114, no. 2, pp. 599-603, 2006.

[18] H. Wei, X. Yan, S. Wu, Z. Luo, S. Wei, and Z. Guo, "Electropolymerized polyaniline stabilized tungsten oxide nanocomposite films: electrochromic behavior and electrochemical energy storage," The Journal of Physical Chemistry C, vol. 116, no. 47, pp. 25052-25064, 2012.

[19] B.-X. Zou, Y. Liang, X.-X. Liu, D. Diamond, and K.-T. Lau, "Electrodeposition and pseudocapacitive properties of tungsten oxide/polyaniline composite," Journal of Power Sources, vol. 196, no. 10, pp. 4842-4848, 2011.

[20] B.-X. Zou, X.-X. Liu, D. Diamond, and K.-T. Lau, "Electrochemical synthesis of $\mathrm{WO}_{3} / \mathrm{PANI}$ composite for electrocatalytic reduction of iodate," Electrochimica Acta, vol. 55, no. 12, pp. 3915-3920, 2010.

[21] K. Naoi, Y. Oura, M. Maeda, and S. Nakamura, "Electrochemistry of surfactant-doped polypyrrole film(I): formation of columnar structure by electropolymerization," Journal of the Electrochemical Society, vol. 142, no. 2, pp. 417-422, 1995.

[22] C.-H. Yang, Y.-K. Chih, H.-E. Cheng, and C.-H. Chen, "Nanofibers of self-doped polyaniline," Polymer, vol. 46, no. 24, pp. 10688-10698, 2005.

[23] S. Bhadra, S. Chattopadhyay, N. K. Singha, and D. Khastgir, "Improvement of conductivity of electrochemically synthesized polyaniline," Journal of Applied Polymer Science, vol. 108, no. 1, pp. 57-64, 2008.

[24] L. Duić, Z. Mandić, and S. Kovač, "Polymer-dimer distribution in the electrochemical synthesis of polyaniline," Electrochimica Acta, vol. 40, no. 11, pp. 1681-1688, 1995.

[25] E. A. Meulenkamp, "Mechanism of $\mathrm{WO}_{3}$ electrodeposition from peroxy-tungstate solution," Journal of the Electrochemical Society, vol. 144, no. 5, pp. 1664-1671, 1997.

[26] L. Barrio, J. M. Campos-Martín, and J. L. G. Fierro, "Spectroscopic and DFT study of tungstic acid peroxocomplexes," Journal of Physical Chemistry A, vol. 111, no. 11, pp. 2166-2171, 2007. 
[27] M. Deepa, A. K. Srivastava, K. N. Sood, and A. V. Murugan, "Nanostructured tungsten oxide-poly(3,4-ethylenedioxythiophene): poly(styrenesulfonate) hybrid films: synthesis, electrochromic response, and durability characteristics," Journal of the Electrochemical Society, vol. 155, no. 11, pp. D703-D710, 2008.

[28] H.-F. Jiang and X.-X. Liu, "One-dimensional growth and electrochemical properties of polyaniline deposited by a pulse potentiostatic method," Electrochimica Acta, vol. 55, no. 24, pp. 7175-7181, 2010.

[29] K. R. Prasad and N. Miura, "Potentiodynamically deposited nanostructured manganese dioxide as electrode material for electrochemical redox supercapacitors," Journal of Power Sources, vol. 135, no. 1-2, pp. 354-360, 2004.

[30] C. Jo, I. Hwang, J. Lee, C. W. Lee, and S. Yoon, "Investigation of pseudocapacitive charge-storage behavior in highly conductive ordered mesoporous tungsten oxide electrodes," The Journal of Physical Chemistry C, vol. 115, no. 23, pp. 11880-11886, 2011.

[31] Q. Wu, Y. Xu, Z. Yao, A. Liu, and G. Shi, "Supercapacitors based on flexible graphene/polyaniline nanofiber composite films," ACS Nano, vol. 4, no. 4, pp. 1963-1970, 2010.

[32] D. Wang, Y. Li, Q. Wang, and T. Wang, "Nanostructured $\mathrm{Fe}_{2} \mathrm{O}_{3}$-graphene composite as a novel electrode material for supercapacitors," Journal of Solid State Electrochemistry, vol. 16, no. 6, pp. 2095-2102, 2012.

[33] H. Wang, Q. Hao, X. Yang, L. Lu, and X. Wang, "A nanostructured graphene/polyaniline hybrid material for supercapacitors," Nanoscale, vol. 2, no. 10, pp. 2164-2170, 2010.

[34] D. Zhang, X. Zhang, Y. Chen, P. Yu, C. Wang, and Y. $\mathrm{Ma}$, "Enhanced capacitance and rate capability of graphene/ polypyrrole composite as electrode material for supercapacitors," Journal of Power Sources, vol. 196, no. 14, pp. 5990-5996, 2011. 

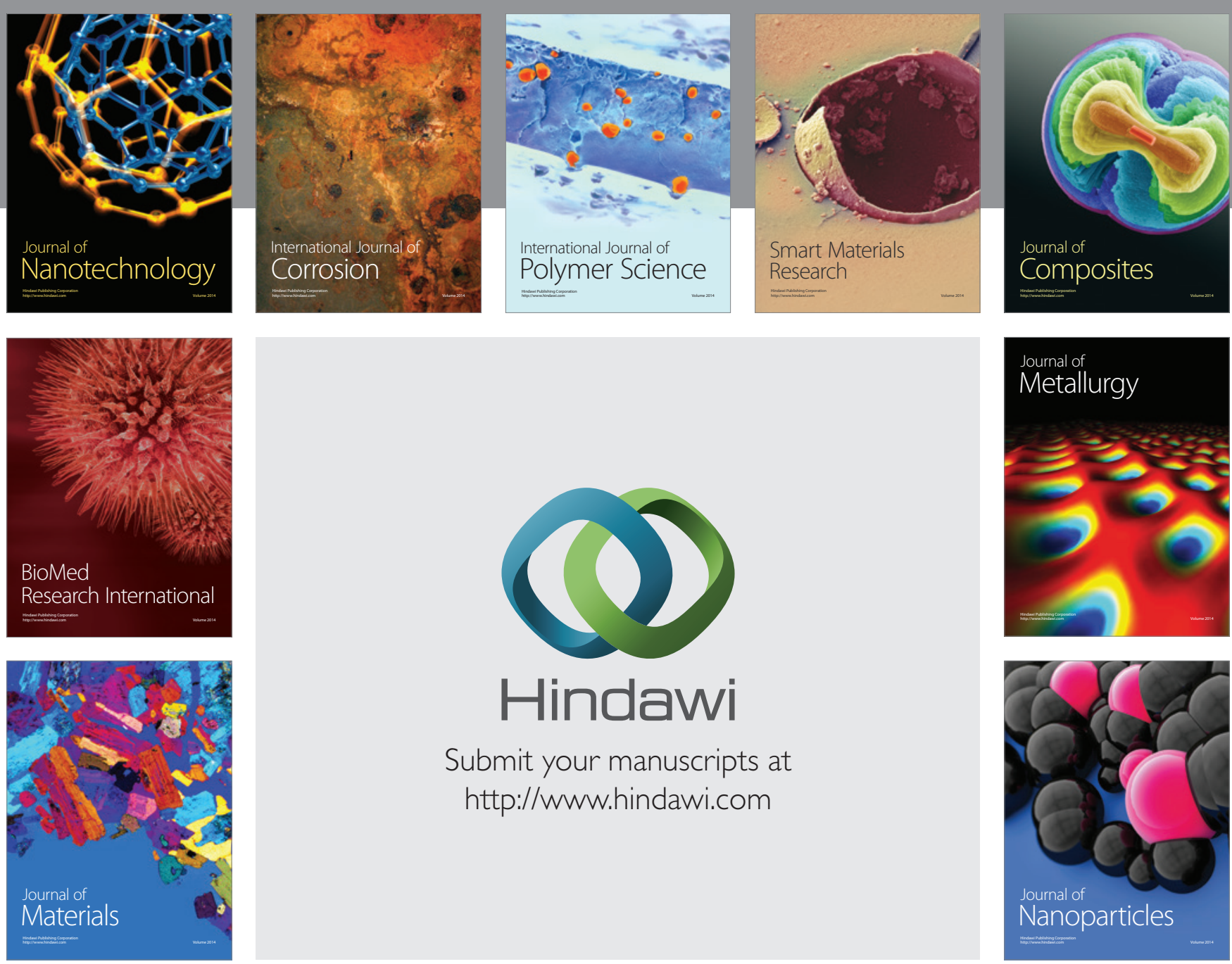

Submit your manuscripts at http://www.hindawi.com
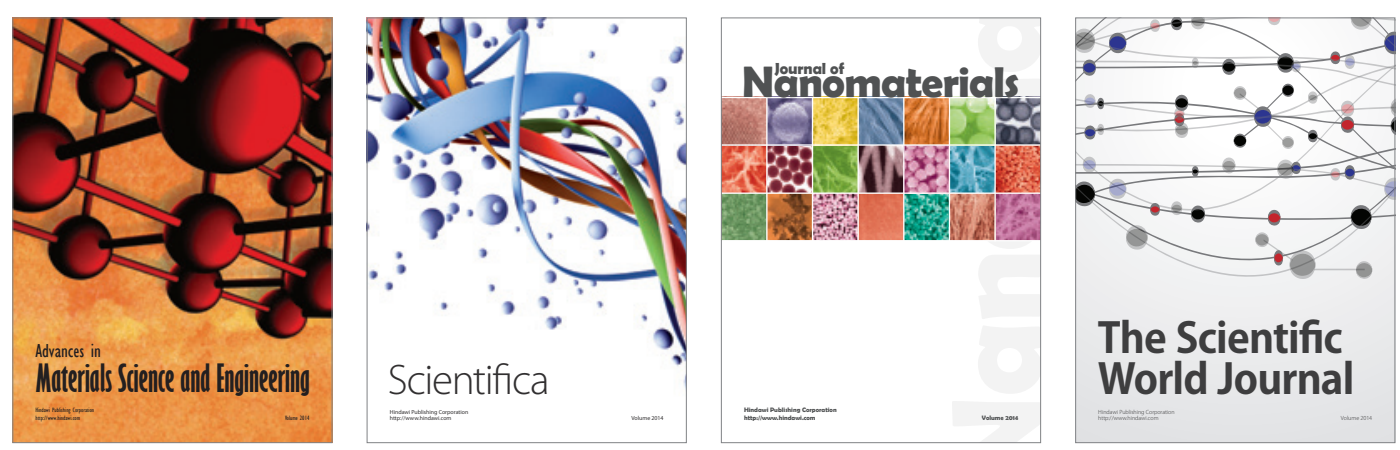

\section{The Scientific World Journal}
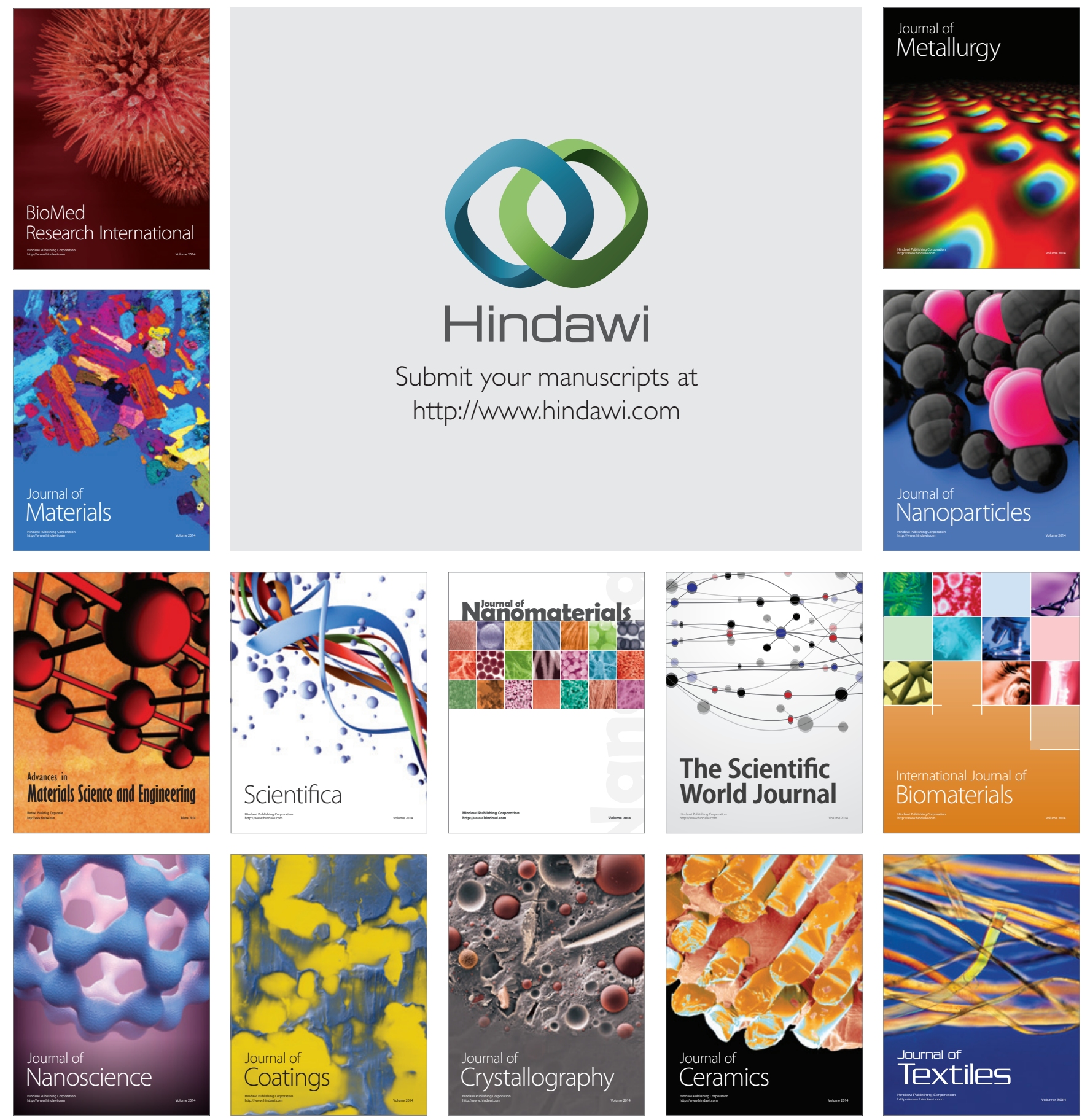